within the synovium or joint cavity, symptoms and signs of joint inflammation fluctuate in intensity, mimicking the intermittent synovitis common in early rheumatoid arthritis.

Histological examination of the synovial fluid precipitate is usually neglected in the investigation of rheumatic disorders. Though it is rarely informative in patients with polyarthritis, it is a pertinent investigation in those with monoarthritis, where failure to recall an initial penetrating injury does not exclude the diagnosis of persistent synovitis induced by foreign material.

${ }^{1}$ Fletcher MR, Scott JT. Chronic monoarticular synovitis: diagnostic and prognostic features. Ann Rheum Dis 1975;34:171-6.

2 Kelly JJ. Blackthorn inflammation. $\mathcal{F}$ Bone foint Surg 1966;3B :474-7.

(Accepted 11 November 1980)

Royal National Hospital for Rheumatic Diseases, Bath BA1 1RI

D R BLAKE, MB, MRCP, senior registrar

P A BACON, MB, FRCP, consultant rheumatologist

Department of Pathology, Royal United Hospital, Bath BA1 3NG C A SCOTT, MRCPATH, senior registrar

A R POTTER, FIMLS, senior chief medical laboratory scientific officer

\section{Controlled trial comparing De-Nol tablets with De-Nol liquid in treatment of duodenal ulcer}

De-Nol (tri-potassium di-citrato bismuthate) is effective in the treatment of duodenal ulcer, ${ }^{1}$ but its usefulness is limited by the unpleasant taste and smell of the liquid formulation. We compared the effectiveness of a new tablet preparation of De-Nol with the established liquid preparation in the treatment of duodenal ulcer.

\section{Patients, methods, and results}

Forty patients with duodenal ulceration proved endoscopically were allocated at random to treatment with De-Nol liquid ( $5 \mathrm{ml}$ four times daily) or De-Nol tablets (1 four times daily) for one month. Patients symptoms were then reassessed and an endoscopic examination conducted by a clinician unaware of their treatment. Bismuth concentrations in blood and urine were measured in all patients before and immediately after treatment and again two weeks after the course of treatment had finished. Patients with renal failure, and those who had undergone surgery for their ulcer or had been treated with cimetidine, De-Nol, or carbenoxolone in the three months before endoscopy were excluded. Patients noted symptoms daily during the course of treatment.

Twenty patients (mean age 43) were treated with De-Nol tablets and twenty (mean age 38 ) with De-Nol liquid. Groups were comparable in age, severity, and duration of symptoms. In the group taking tablets 16 noted improvement of symptoms, and 15 of the ulcers had healed after one month's treatment. Mean time to the relief of symptoms was 18 days. Seventeen patients found the treatment acceptable or pleasant, and three found it unpleasant. In the group treated with De-Nol liquid 16 noted relief of symptoms, and 17 of the ulcers healed. Mean time to the relief of symptoms was 17 days. There were no significant differences between the groups for these indices. Thirteen of those taking liquid found it pleasant or acceptable,

Details of patients and results of treatment with De-Nol tablets and liquid

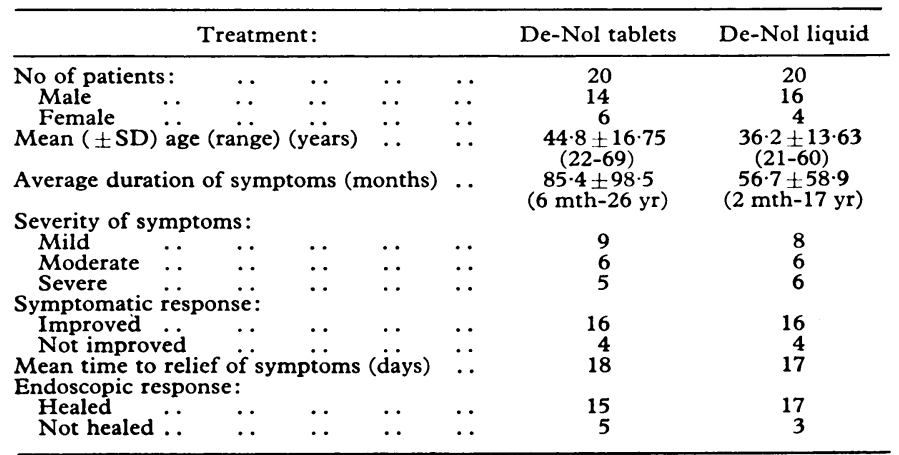

and seven found it unpleasant $(p<0.05)$, but none failed to complete the course of treatment. No patient complained of major side effects. Two taking tablets complained of constipation, and one in each group complained of a sore mouth. Two patients taking tablets complained of mouth staining, which was found on questioning to have affected 15 patients taking tablets and six taking liquid $(p<0.05)$. Serum bismuth concentrations rose slightly in only two patients and fell after treatment had stopped. The highest concentration recorded was $120 \mathrm{nmol} / 1(25 \mu \mathrm{g} / \mathrm{l})$ in one patient. There was no difference between the groups.

\section{Comment}

De-Nol tablets are as effective as the established liquid preparation of De-Nol in the treatment of duodenal ulcer, and the proportion of ulcers healed in each group compares favourably with other agents. De-Nol in both the liquid ${ }^{2}$ and tablet ${ }^{3}$ forms has been shown to be as effective as cimetidine in the treatment of duodenal ulcer, and a recent report suggests that the relapse rate after De-Nol treatment may be lower (D F Martin, et al, British Society of Gastroenterology meeting, 1980).

Side effects in this trial were minor, and appreciable absorption of bismuth did not occur. Bismuth neurotoxicity occurs when serum concentrations exceed $479 \mathrm{nmol} / \mathrm{l}(100 \mu \mathrm{g} / \mathrm{l}),{ }^{4}$ concentrations below $239 \mathrm{nmol} / 1(50 \mu \mathrm{g} / \mathrm{l})$ being considered safe, and no patient in our study reached these values. Neurotoxicity has never been reported in a patient taking De-Nol.

De-Nol treats duodenal ulcers effectively and does so without systemic absorption or side effects and without rendering the stomach achlorhydric. The development of an equally effective tablet formulation which more patients find acceptable is an important advance in the medical treatment of duodenal ulcer.

We are grateful to Brocades (GB) Ltd for supplies of De-Nol and to Mrs C L Baxendale for typing the manuscript.

${ }^{1}$ Moshal MG. The treatment of duodenal ulcer with tri-potassium dicitrato bismuthate. Postgrad Med F 1975;51 suppl 5:36-40.

${ }^{2}$ Martin DF, Hollanders D, Miller JP, May SJ, Tweedle DEF, Ravenscroft MM. Comparison between cimetidine and De-Nol in duodenal ulcer healing. Gut 1979;20:A904.

${ }^{3}$ Vantrappen G, Rutgeerts P, Broekaert L, Janssens J. Randomised open controlled trial of colloidal bismuth subcitrate tablets and cimetidine in the treatment of duodenal ulcer. Gut $1980 ; 21: 329-33$.

${ }^{4}$ Loisseau P, Henry P, Jallon P, Legroux M. Encephalopathies myocloniques iatrogènes par les sels de bismuth. F Neurol Sci 1976;7:133-43.

(Accepted 11 November 1980)

Gastroenterology Unit, General Infirmary, Leeds LS1 3EX

I HAMILTON, MB, MRCP, medical registrar

A T R AXON, MD, FRCP, consultant physician

\section{Successful treatment of D-penicillamine-induced breast gigantism with danazol}

D-Penicillamine may cause sudden breast gigantism. ${ }^{1}$ Danazol (17 $\alpha$-pregna-2,4-dien-20-ynol [2,3-d] isoxazol-17 $\beta$-ol) has been used to manage benign breast disease. ${ }^{2}$ This report describes the endocrine profile, regimen of danazol, and outcome in a patient with breast gigantism induced by $\mathbf{D}$-penicillamine.

\section{Case report}

In January 1976 a 41-year-old nulliparous woman who suffered from rheumatoid arthritis began taking D-penicillamine $750 \mathrm{mg}$ daily. In July 1977 she began to complain of breast enlargement. In June 1978 she discontinued the D-penicillamine for three weeks. There was no reduction in the size of her breasts and she had severe swelling of both knees. The Dpenicillamine was restarted. In October 1978, after a further slight increase in the size of her breasts, the D-penicillamine was discontinued. Treatment with indomethacin was started and in January 1979 was changed to naproxen $250 \mathrm{mg}$ three times a day. In February 1979, five months after the last exposure to D-penicillamine, the patient was admitted to hospital with 